\title{
Clinical survey done to find out the acceptability of modified and innovative neutropenic diet among hospitalized patients suffering with neutropenic and immune suppressed conditions
}

\section{Poonam Tiwari*}

\begin{abstract}
Department of Dietetics, Dr. Ram Manohar Lohia Institute of Medical Sciences, Gomti Nagar, Lucknow, Uttar Pradesh, India
\end{abstract}

Received: 01 March 2016

Accepted: 06 April 2016

\author{
*Correspondence: \\ Poonam Tiwari, \\ E-mail: poonam.prisha@gmail.com
}

Copyright: () the author(s), publisher and licensee Medip Academy. This is an open-access article distributed under the terms of the Creative Commons Attribution Non-Commercial License, which permits unrestricted non-commercial use, distribution, and reproduction in any medium, provided the original work is properly cited.

\begin{abstract}
Background: Traditional neutropenic diets are normally quite monotous, unpalatable and unpleasant. Therefore following study was done to analyse and find out various methods and strategies to prevent food borne illnesses or infection in such patients. In following study the conventional neutropenic diet is modified in terms of content, preparation and service. Main approach towards patient was to maintain patient's nutritional status, to enhance their appetite, to break monotony of diet.

Methods: In the present case report, case studies of 25 patients were included who were provided safe and hygienic diet from the kitchen and were counselled by the dietetic department. They were also categorized as immune suppressed patients. At every step we checked the quality as well as the hygiene of food provided to the patients.

Results: In the above study majority of the patients were quite active and supportive with the innovations and modifications done in their daily meal plan. With severe mucositis and lack of appetite still the tried to eat seeing the presentation and changes in daily menu. Through this study integrated approach and wholesomeness of quality has been emphasised in order to give the quality dietary services to the admitted patients.

Conclusions: The relevance of the study in such areas is quite important and needed. The methodological step involved right from the procurement of the raw food till delivery of food to the patients is the most preferred form in order to achieve their satisfaction index. Therefore, such practice is on-going process.
\end{abstract}

Keywords: Neutropenia, Innovative recipes, Hygienic diet, Wholesomeness of quality

\section{INTRODUCTION}

Neutropenia term is derived from neutro- ("neither", for neutral staining) and - $\pi \varepsilon v i ́ \alpha$ (-penía, "deficiency"). ${ }^{4}$ This is a disorder characterized by an abnormally low number of neutrophils. Our circulating blood contains Neutrophils usually up to 60 to $70 \%$. Their main function is to serve as the primary defence against infections by destroying bacteria in the blood. These cells are produced in the bone marrow. While circulating in blood they specifically function at various sites of infection. They release chemicals to kill invading microorganisms. Hence, patients with neutropenia are more prone to bacterial infections and, without prompt medical attention, the condition may become life-threatening and deadly (neutropenic sepsis). ${ }^{1,4}$ Henceforth, patient suffering from neutropenia or any immune suppressed condition needs utmost care during hospital stay. Any compromise or negligence in hygiene and safety may be fatal or might lengthen the hospital stay.

The Neutropenic diet serves the purpose to reduce the amount of food introduced into the body that has high levels of bacteria. ${ }^{2,3}$ While there are many good bacteria in our food there are also many bad bacteria. Healthy people have immune systems that can easily deal with the 
bad bacteria, but such is not the case for those with suppressed immune function. Traditional neutropenic diets are normally quite monotous, unpalatable and unpleasant. $^{3}$ Therefore following study was done to analyse and find out various methods and strategies to prevent food borne illnesses or infection in such patients. In following study the conventional neutropenic diet is modified in terms of content, preparation and service

Dietary interventions and their advantages in therapeutic field are best assessed with the help of anthropometric parameter, biochemical parameter, clinical parameter and dietary recall. ${ }^{6}$ In the present case study dietary recall was chosen for the reason that patient's dietary intake was directly proportional with his/her ability to accept food and also their acceptance was carefully recorded for various innovations done in the meals. ${ }^{8}$

The aim of our study was to increase the patient's appetite as well as to maintain their nutritional status through providing diet in very sterile and hygienic condition as well as by incorporating innovative nutritional recipes such as Jaggery rice kheer, apple halwa, suji halwa without milk. Main approach towards patient was:

- To maintain patient's nutritional status

- To enhance their appetite

- To break monotony of diet.

\section{METHODS}

In the present case report, case studies of 25 patients were included who were provided safe and hygienic diet from the kitchen and were counseled by the dietetic department. These patients were diagnosed with Aplastic anemia, Acute myelomas etc. They were also categorized as immune suppressed patients. Case studies included patient's admitted in 2009 till 2014. These patients were telephonically interviewed on the basis of common questionnaire as well as were taken as individual case studies by the dietary interns under the supervision of chief dietician. This enabled us to summarize minute details related to patients stay. To provide a hygienic diet following measure were taken in the hospital's kitchen, which involved co-operation and dedication of chefs, stewards, patients, nursing and dietetic department. ${ }^{11}$ At every step we checked the quality as well as the hygiene of food provided to the patients.

\section{Measures:}

\section{Lab testing of food to check the presence of adulterants in the various food products, as followed}

- Metanil yellow (as an adulterant), in gram flour.

- Papaya seeds (as an adulterant), in black pepper seeds.

- Colouring matter (as an adulterant), in red chili powder.
- Metanil yellow (as an adulterant), in jaggery.

- $\quad$ Sand and Talcum powder (as an adulterant), in sago.

- Scented resins or Gums (as an adulterant), in asafetida.

- Talcum powder (as an adulterant), in cardamom.

- Metanil yellow (as an adulterant), in arhar and moong dal.

- Metanil yellow (as an adulterant), in turmeric powder.

Quality check of the following perishable food products

- $\quad$ Milk.

- $\quad$ Egg.

- Vegetables \& Fruits.

On the basis of

- Temperature.

- Physical appearance.

- Smell.

- $\quad$ Shelf life.

Techniques used

- Dilution of milk is checked by lactometer test.

- Quality checking of Eggs is done by floating test.

- Vegetables \& Fruits are made sterile by dipping in chlorotip solution, 12 before washing.

\section{Hygiene of food from preparation till serving}

\section{Quality checking of food preparation}

Foods served are wrapped with aluminium foil and then packed by a clean film so as to give the utmost importance to the hygiene of a diet provided for the patients.

On the basis of

- Hygienic way of cooking.

- Clean packaging.

Quality check of food while serving:

On the basis of:

- Presentation.

- Use of appropriate utensils and cutleries (use of disposables is strictly prohibited, until asked).

- Use of proper serving utensils.

- Labelling of a particular diet.

- Proper wrapping.

- Use of head covers, hand gloves and face masks are made to minimize the contamination to the core.

\section{Quality check of food items in front of the patients}

On the basis of 
- Patient's preference.

- Quantity served.

- Physical assessment of the served food (e.g. fall of any fly or insects), which may be infectious to their health/the food served is fresh.

- Use of head covers, hand gloves, face masks \& aprons is followed by the service men and the consultant dieticians so that the patients may not get into contact with any sort of contamination which may lead various ill effects to the patients' health.

\section{Innovative modifications in dietary recipes}

Incorporation of various recipes was done to break the monotony. $^{7}$

\section{On the basis of}

- Nutritional value.

- Acceptability.

- Appeal.

Recipes prepared

- Jaggery Rice kheer.

- Apple halwa without milk.

- Suji halwa without milk.

To create wholesomeness in the standard and quality served, monthly classes are conducted for the workers of the hospital's kitchen and serving department

To maintain continuity in the quality service, monthly briefing with poster display of the dietary norms are given to the workers of the hospital`s kitchen and serving department by the consultant dieticians.

Counselling of patients is also done

On the basis of

- Lessons about hygienic preparation of diet.

- Neutropenic diets.

- Modifications of diet to overcome with the problem of concerned patient.

\section{RESULTS}

The graph depicts the patient's response related to the acceptance of the hospital served diet. Majority of them liked the food and also appreciated in the way it was served (Figure 1).

Hygienic handling of the food was appreciated by maximum no of patients. This ensures that the efforts to make food safe were done well by the kitchen staff (Figure 2).

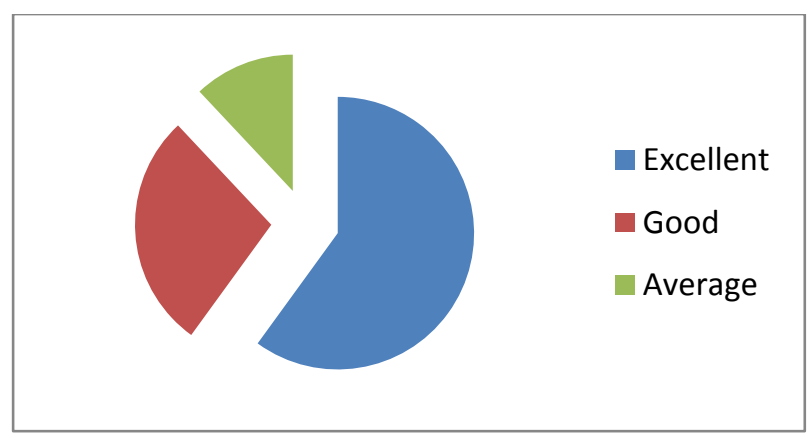

Figure 1: Representation of question 1.

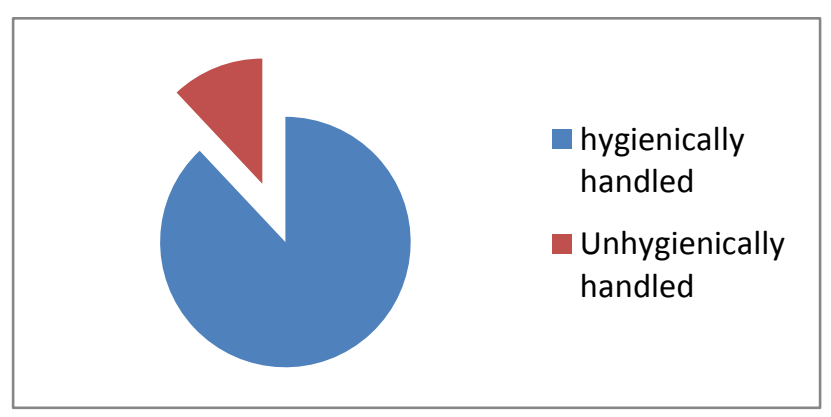

Figure 2: Representation of question 2.

Diet counseling done for these patients helped them to understand their disease well and also taught them how to sustain their appetite despite of having mucositis and loss of appetite (Figure 3).

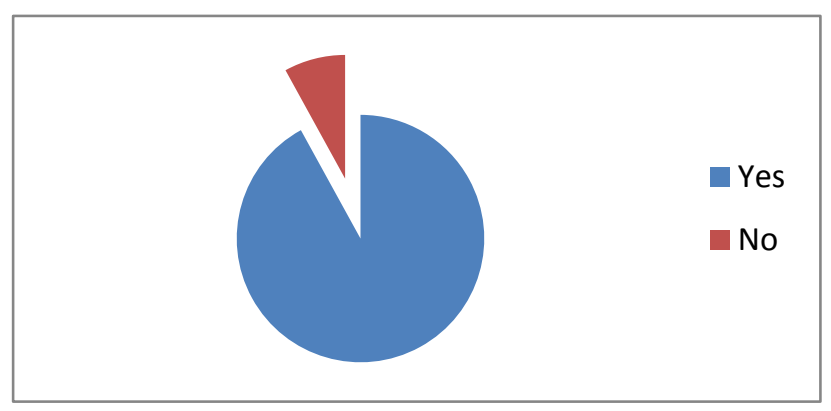

Figure 3: Representation of question 3.

Affordable, available nutritious innovative recipes were incorporated in patient's meal plan and these were also liked by them. Only few couldn't relish the recipes because they lack the palatability for the same and were not accustomed of them (Figure 4).

Patients were quite satisfied with the meal plan as they found as per their choices only few were unhappy because the choice the expressed were not nutritionally beneficial for them so keeping patient's health at priority they were excluded from the diet (Figure 5).

Team effort were quite helpful to provide patient diets as per their appetite small and frequent meals were possible due to the support of the kitchen staff and the prompt service were done by the stewards (Figure 6). 


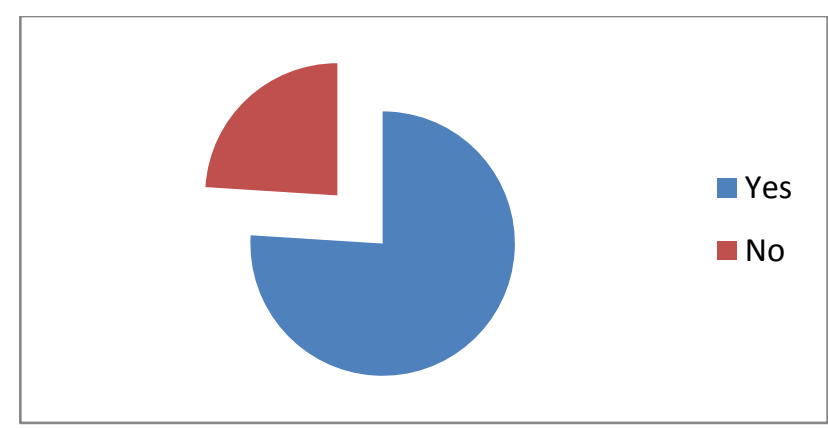

Figure 4: Representation of question 4.

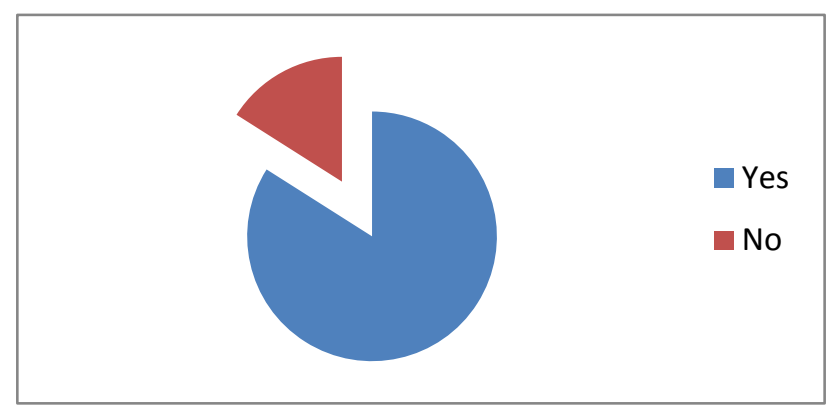

Figure 5: Representation of question 5.

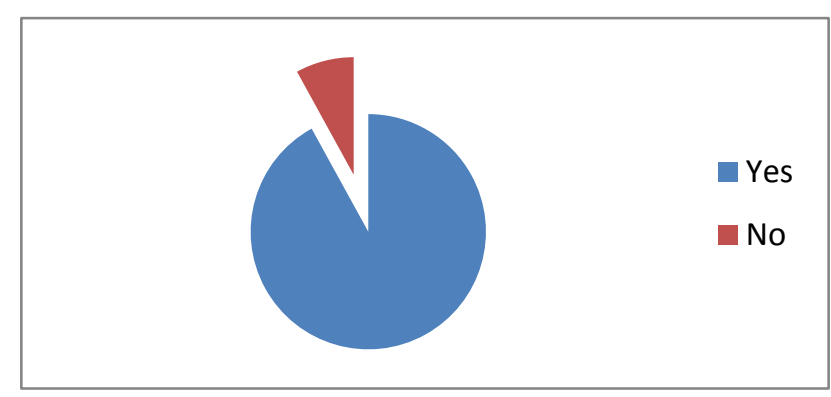

Figure 6: Representation of question 6.

Dietician of the respective wards use to pay regular visit so as to know the patient's feedback after each meal and accordingly next day's diet was planned (Figure 7).

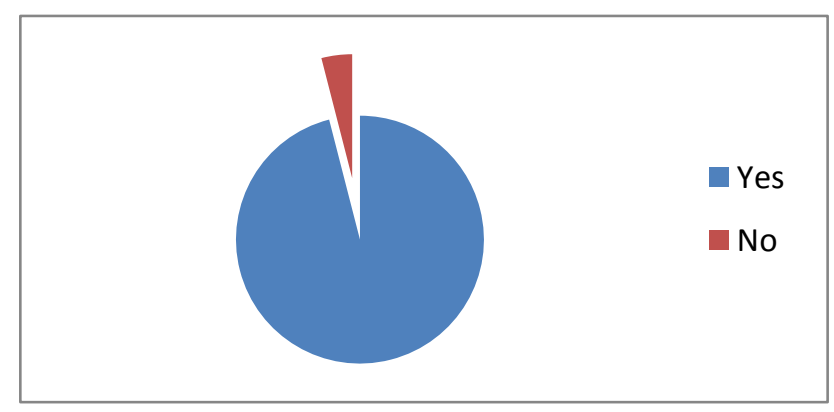

Figure 7: Representation of question 7.

Maximum no of patients showed the increase pattern of weight gain although the increase was quite marginal (Figure 8).

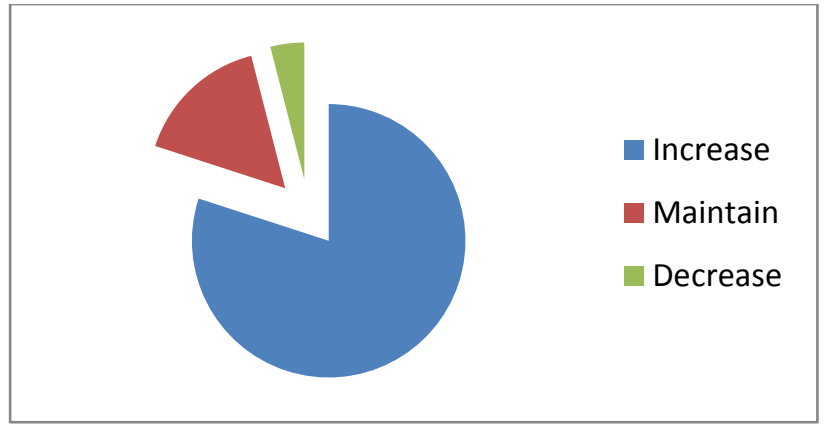

Figure 8: Representation of question 8.

\section{DISCUSSION}

The methodology and the systematic approach in present study can be implemented and executed on regular basis in any bulk cooking areas. The relevance of the study in such areas is quite important and needed. The methodological step involved right from the procurement of the raw food till delivery of food to the patients is the most preferred form in order to achieve their satisfaction index. Therefore, such practice is on-going process. This study is unique because it has involved various facilities available in the kitchen as well as hospital and has channelized these facilities to obtain substantial result. For e.g. Microbiological lab's in hospitals, simple reagents were applied to rule out presence of any adulterant present in some food products. Right from the utility worker of the kitchen to the dietician level everybody's unified efforts helped department to provide hygienic and safe food to the patients.

This project has tried to encompass all the check points to ensure the hygiene and safety of food, but to ensure maximum safety and hygiene, following suggestions are valuable which can be included in its larger application elsewhere. ${ }^{9,10}$

- Microbial analysis of the cooked food is also desirable to rule any microbial growth in food. (In present study food items were discarded if found stale or were not eaten by the patient for long time).

- Separate cooking area along with exclusively trained personnel should be preferred so as to avoid cross contamination (in present study the cooking area is cleaned and utensils are washed separately).

- Serving and cooking utensils should be procured separately and even sterile to avoid any contamination.

- While planning diet we should consider the dietary pattern of the patient so that innovations in their diet could be as per patient's taste and acceptability. ${ }^{5}$

- Nutrition education and counselling of the patient along with the family should be encouraged as diet 
plays a very significant role in patient's immune suppressed condition and such precautions are desirable at home also.

\section{ACKNOWLEDGEMENTS}

For the completion of this case report my acknowledgements are due to the hospital authorities, Kitchen staff and personnel, dietetics department and the admitted patients. I would also like to deeply express my gratitude towards Ms. Aishwarya Srivastava and Ms. Shreya Chaubey for formatting the report and with the compilation work

Funding: No funding sources Conflict of interest: None declared

Ethical approval: Not required

\section{REFERENCES}

1. Neutropenia. Available at https://en.wikipedia.org / wiki. Accessed 20 February 2016.

2. Foster M. Reevaluating the Neutropenic Diet: time to Change. Clin J Oncol Nurs. 2014;18(2):239-41.

3. Jubelirer JS. The Benefit of the Neutropenic Diet: fact or fiction. Oncologist. 2011;16(5):704-7.

4. Neutropenic. Available at http://www.it1me.com / learn? s. Accessed 15 February 2016.

5. Nutrition Support for Adults: Oral Nutrition Support, Enteral Tube Feeding and Parenteral Nutrition.Available at http://www.ncbi.nlm.nih.gov / books/ NBK49279/. Accessed 18 February 2016.

6. Food and Nutritional Care in Hospitals. Guidelines for preventing under-nutrition in acute hospitals. published by the department of health and children april 2009.Available at http://health.gov.ie / wpcontent / uploads / 2014 / 03 / undernutrition_ hospital_guidelines.pdf. Accessed 18 January 2016.

7. Food in Hospitals: National Catering and Nutrition Specification for Food and Fluid Provision in Hospitals in Scotland 2008. Available at http://www.gov.scot / Publications / 2008 / 06 / 24145312 / 8. Accessed 15 February 2016.

8. Nutritional Guidelines for Symptom Management. Available at http://www.bccancer.bc.ca/nutritionsite/Documents/Mucositis.pdf. Accessed 10 February 2016.

9. Lalla RV, Sonis ST, Peterson DE. Management of Oral Mucositis in Patients with Cancer. Dent Clin North Am. 2008;52(1):61-viii.

10. Nutrition in Cancer Care-for health professionals (PDQ®). Available at http://www.cancer.gov/aboutcancer/treatment/side-effects/appetite-loss/nutritionhp-pdq. Accessed 20 January 2016.

11. Lazarevic K, Stojanovic D, Bogdanovic CD, Dolicanin CZ. Hygiene training of food handlers in hospital settings:important factor in the prevention of nosocomial infections. Cent Eur J Public Health 2013;21(3):146-9.

12. Chlorotip. Sanitizing Tablets. Available at http://www.rainchem.com/pdf/kitchenproductsheet/ chlorotip_ps.pdf. Accessed 20 January 2016.

Cite this article as: Tiwari P. Clinical survey done to find out the acceptability of modified and innovative neutropenic diet among hospitalized patients suffering with neutropenic and immune suppressed conditions. Int J Community Med Public Health 2016;3:1173-7. 